Article

\title{
Analysis of Metabolites in White Flowers of Magnolia Denudata Desr. and Violet Flowers of Magnolia Liliiflora Desr.
}

\author{
Chang Ha Park ${ }^{1}$, Soo-Yun Park ${ }^{2}$, Sook Young Lee ${ }^{3}$, Jae Kwang Kim ${ }^{4, * \mathbb{C}}$ and Sang Un Park ${ }^{1, *}$ \\ 1 Department of Crop Science, Chungnam National University, 99 Daehak-Ro, Yuseong-gu, \\ Daejeon 34134, Korea; parkch804@gmail.com \\ 2 National Institute of Agricultural Sciences, Rural Development Administration, Wanju-gun, \\ Jeonbuk 54875, Korea; psy22@korea.kr \\ 3 Regional Innovation Center for Dental Science \& Engineering, Chosun University, 309 Pilmun-daero, \\ Dong-gu, Gwangju 501-759, Korea; koreanseedbank@gmail.com \\ 4 Division of Life Sciences and Bio-Resource and Environmental Center, Incheon National University, \\ Incheon 406-772, Korea \\ * Correspondence: kjkpj@inu.ac.kr (J.K.K.); supark@cnu.ac.kr (S.U.P.); Tel.: +82-32-835-8241 (J.K.K.); \\ +82-42-821-6730 (S.U.P.); Fax: +82-32-835-0763 (J.K.K.); +82-42-822-2631 (S.U.P.)
}

Received: 27 May 2018; Accepted: 21 June 2018; Published: 27 June 2018

\begin{abstract}
A total of seven phenolics and 44 metabolites was profiled in white flowers of Magnolia denudata and violet flowers of Magnolia liliiflora using high-performance liquid chromatography (HPLC), electrospray ionization-mass spectrometry (ESI-MS), and gas chromatography time-of-flight mass spectrometry (GC-TOFMS). Seven phenylpropanoid compounds were identified in white flowers by liquid chromatography mass spectrometry (LC-MS). An HPLC analysis showed that phenylpropanoid accumulation in violet flowers was 1.48 times higher than that in white flowers. Furthermore, superoxide dismutase (SOD)-like activity and 1,1-diphenyl-2-picrylhydrazyl (DPPH) radical scavenging activity were determined to investigate the antioxidant properties of secondary metabolites in different flowers. Violet flowers showed higher SOD-like and DPPH activity than white flowers. In addition, anti-inflammatory activity measured using a nitric oxide assay was higher in violet flowers than in white flowers. Our results provide valuable information on the relationship between primary and secondary metabolites, and synergistic antioxidant and anti-inflammatory properties derived from phenolic compounds in different colored flowers.
\end{abstract}

Keywords: Magnolia denudata Desr.; Magnolia liliiflora Desr.; flowers; metabolic analysis

\section{Introduction}

Magnolia, the largest genus in the Magnoliaceae family with more than 128 species, is widely distributed in East and Southeast Asia. These plants typically produce a large number of highly fragrant, cup shaped, and conspicuous flowers [1,2]. In Asian herbal medicine, Magnolia flowers and bark have been used to treat symptoms such as headache, thrombotic stroke, gastrointestinal disorders, anxiety, and allergies $[3,4]$. The use as a medicinal product is based on a substantial number of different phytochemicals with anxiolytic [4], antiplatelet [5], antipyretic [6], anti-inflammatory [6], antidiarrheal [7], antioxidant [7], anti-stomach ulcer [8], and anti-allergic properties [9]. Magnolia denudata Desr. and Magnolia liliiflora Desr. are commonly used as ornamental plants due to their attractive flowers; however, they are also utilized in traditional medicine (Figure 1). Traditionally, Magnolia denudata Desr. has been used as analgesic agent treating headache caused 
by sinusitis, nasal congestion, and allergic rhinitis [10,11]. Similarly, Magnolia liliiflora Desr has been used for treatment of headache, lumbago, and rhinitis [12].

Flavonoids are phenolic compounds commonly found in plants, and can be categorized in six classes: anthocyanins, isoflavones, flavones, flavanones, flavanols, and flavanonols [13]. The flavonoids play a crucial role for the development, growth, and pigment production of plants [14,15]. Moreover, these compounds are important for the protection of plants against environmental biological and physical stressors, including pathogen assault, insect herbivory, wounding, ultraviolet (UV) radiation, excessive light, and water deficiency [14-16]. Anthocyanins, belonging to flavonoids, are plant pigments exhibiting blue, pink, orange, violet, or red color in plant organs. Although a vast number of anthocyanins occurs naturally, six particular anthocyanidins (including petunidin, malvidin, peonidin, pelargonidin, cyanidin, and delphinidin) are the most common pigment compounds in vascular plants [17-19]. Studies on the biological activities of flavonoids showed a diversity of biological characteristics, such as antimicrobial, anti-inflammatory, anticarcinogenic, and antiviral, and antioxidant activities [20,21].

Metabolomic profiling has provided vital information for systematic botany by qualitative and quantitative measurement of various cellular metabolites [22-24]. Such measurements have been performed successfully using chromatography-mass spectrometry systems, which have facilitated the detection of numerous metabolites and their full or partial isolation [25]. Among these systems, liquid chromatography mass spectrometry (LC-MS) has been employed most frequently to detect metabolites of relatively high-molecular-weight, which cannot be analyzed using gas chromatography (GC) [26]. The method of GC time-of-flight mass spectrometry (GC-TOFMS) operates under fast scan time, and produces high mass accuracy and resolution for the detection of metabolites of relatively low molecular weight $\left(<1000 \mathrm{Da}^{1}\right)[27,28]$.

RAW 264.7 is the murine macrophage cell line used for screening natural products for biological activity and for predicting their potential effect on primary cells or in vivo. The RAW 264.7 cell line response is used to determine the effective biological activity and regarded as a reflection of the potential human de novo response [29].

To our knowledge, to date, no study has investigated the relationship between primary and secondary metabolites in white flowers of $M$. denudata and violet flowers of $M$. liliiflora. The aim of this study was to elucidate the relationship between large numbers of primary and secondary metabolites in white and violet flowers using HPLC, LC-MS, and GC-TOFMS in combination with chemometrics. Furthermore, we investigate the relationship between these metabolites and antioxidant activity.
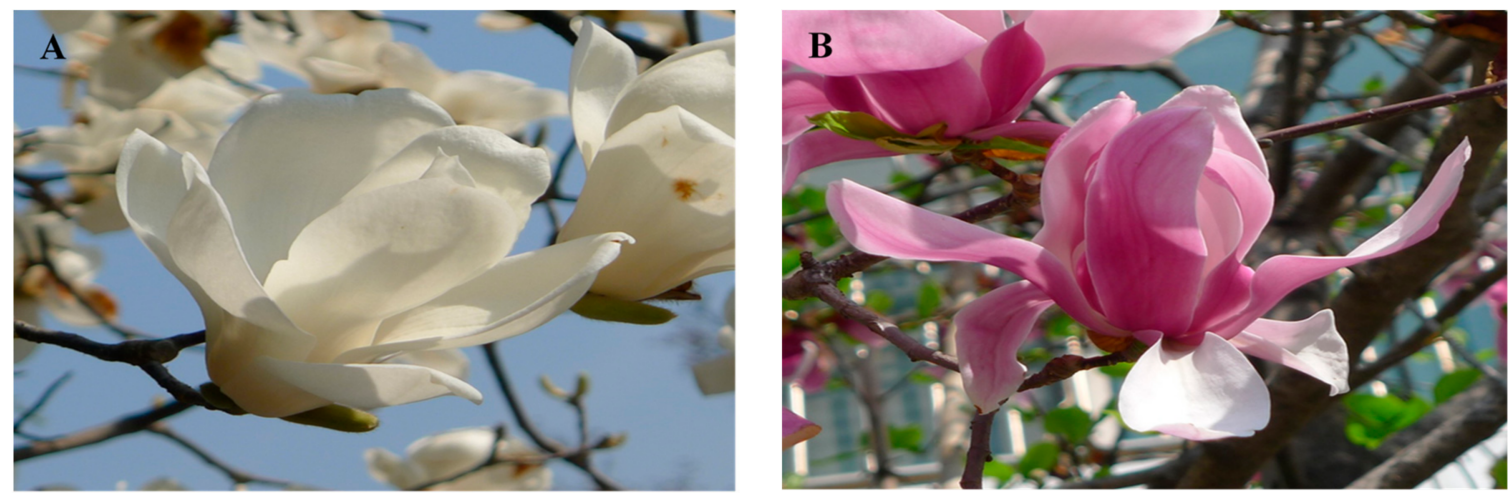

Figure 1. Two different colored flowers. (A) White flowers of M. denudata; (B) Violet flowers of $M$. liliiflora. 


\section{Results and Discussion}

\subsection{LC-MS and HPLC Analysis}

A total of seven phenolic compounds, including three flavonoids and four phenolic acids, was identified in the flowers of M. denudata. by LC-MS analysis (Table 1). Three flavonoids (rutin, quercetin, and kaempferol) were identified as negatively monocharged molecular ions, and four phenolic acids (4-hydroxybenzoic acid, chlorogenic acid, caffeic acid, and $p$-coumaric acid) were identified as negatively monocharged molecular ions (Figure S1 and Table 1).

Seven of the phenolic compounds were identified and quantitated in the different colored Magnolia flowers by comparison of retention time, spike tests, and external standard calibration curves using HPLC (Table 1). Violet flowers contained higher concentrations of total flavonoids $(17.31 \pm 2.39 \mathrm{mg} / \mathrm{g}$ dry weight (wt.)) which is 1.48 times the concentration found in white flowers $(11.71 \pm 0.46 \mathrm{mg} / \mathrm{g}(\mathrm{wt}$.)). Furthermore, a comparison of individual phenolic compounds revealed that violet flowers contained higher amounts of 4-hydroxybenzoic acid, chlorogenic acid, caffeic acid, $p$-coumaric acid, and rutin than those of white flowers, respectively. On the other hand, the unknown compound, showed the largest peak area, was detected (Figure S1).

Table 1. Phenylpropanoid contents (mg/g dry wt.) of white flowers of M. denudata and violet flowers of M. liliiflora.

\begin{tabular}{|c|c|c|c|c|c|}
\hline No. & Retention Time & Phenolics & {$[\mathbf{M}-\mathbf{H}]^{-}(m / z)$} & White & Violet \\
\hline 1 & 20.98 & $\begin{array}{l}\text { 4-hydroxybenzoic } \\
\text { acid }\end{array}$ & 137.6 & $0.27 \pm 0.02$ & $1.20 \pm 0.46^{*}$ \\
\hline 2 & 22.85 & Chlorogenic acid & 353.8 & $0.47 \pm 0.10$ & $1.69 \pm 0.42 *$ \\
\hline 3 & 27.78 & Caffeic acid & 179.9 & $\operatorname{tr}^{1}$ & $0.04 \pm 0.00 *$ \\
\hline 4 & 41.71 & $p$-coumaric acid & 163.4 & $\operatorname{tr}$ & $0.26 \pm 0.04 *$ \\
\hline 5 & 61.99 & Rutin & 609.0 & $10.47 \pm 0.34$ & $13.62 \pm 1.45 *$ \\
\hline 6 & 73.66 & Quercetin & 301.1 & $0.38 \pm 0.00$ & $0.37 \pm 0.00$ \\
\hline \multirow[t]{2}{*}{7} & 80.36 & Kaempferol & 285.5 & $0.12 \pm 0.00$ & $0.13 \pm 0.02$ \\
\hline & & Total & & $11.71 \pm 0.46$ & $17.31 \pm 2.39 *$ \\
\hline
\end{tabular}

\subsection{Total Phenolic and Anthocyanin Contents}

Total phenolic and anthocyanin contents of white and violet flowers, respectively, were measured using the Folin-Denis assay and total anthocyanin content assay. Violet flowers contained 1.20 times higher amount of total phenolics than that in white flowers. Furthermore, anthocyanin concentrations were 3.71 times higher in violet flowers than in white flowers (Table 2).

Table 2. Total polyphenolic and anthocyanin contents in ethanol extracts of white flowers of $M$. denudata and violet flowers of $M$. liliiflora.

\begin{tabular}{ccc}
\hline & Total Phenolics $(\mathbf{m g} / \mathbf{g})$ & Total Anthocyanin $(\mathbf{m g} / \mathbf{g})$ \\
\hline Violet Flowers & $16.94 \pm 0.71^{*}$ & $0.78 \pm 0.16^{*}$ \\
White Flowers & $14.07 \pm 0.55$ & $0.21 \pm 0.08$ \\
\hline
\end{tabular}

Asterisks indicate significant differences (Student's $t$-test, ${ }^{*} p<0.05$ ).

\subsection{GC-TOFMS Analysis}

A total of 44 hydrophilic metabolites identified in white flowers of $M$. denudata and violet flowers of $M$. liliiflora was quantitated using selected ions. After normalization based on signal intensity of an internal standard, a principal component analysis (PCA) was performed to investigate on differences in quantitative metabolite profiles between the two flowers. A component score plot of the PCA results shows an overview of the differences between the two different colored flowers and 
a component pattern plot was constructed to examine the correlations between the 44 metabolites (Figure S2). The samples were differentiated by the two highest ranked components, with the first component explaining $70.69 \%$ of the total variance, thereby separating the metabolite profiles of violet and white flowers. This effect is predominantly due to amino acids and sugars, as the respective loading was negative for most carbohydrates, except for trehalose, raffinose, and mannitol, and positive for most amino acids, except for 4-aminobutyric acid and glutamic acid. The results of PCA showed higher carbohydrate concentrations in violet flowers than in white flowers, and higher amino acid concentrations in white flowers than in violet flowers.

Furthermore, hierarchical cluster analysis (HCA) was performed using Pearson's correlation results in order to examine the relationships between metabolites of white flowers of M. denudata and violet flowers of $M$. liliiflora. The results of HCA revealed the degree of correlation among 51 metabolites, which were identified and quantitated by GC-TOFMS and HPLC. A total of 51 metabolites was clustered together by the HCA using the Pearson's correlation and average linkage clustering method, and marked by dashed-line boxes (Figure 2). One group contained the highest amount of amino acids (except 4-aminobutyric acid and glutamic acid), whereas the other group contained all sugars (except mannitol, trehalose, and raffinose), and phenolic compounds (except sinapic acid and quercetin). These results confirm the loadings found in the PCA. Most Pearson's correlation coefficients between sugars and phenolic compounds exceeded 0.8. A significantly positive relationship was observed between sucrose, which is involved in phenylpropanoid biosynthesis, and phenolics, including 4-hydroxybenzoic acid $(r=0.90532, p=0.013)$, chlorogenic acid $(r=0.9397, p=0.0053)$, caffeic acid $(r=0.94274, p=0.0048), p$-coumaric acid $(r=0.95664, p=0.0028)$, rutin $(r=0.91394, p=0.0108)$, and quinic acid $(r=0.98037, p=0.0006)$. Among phenolics, vanillic acid was positively correlated with caffeic acid, quinic acid, $p$-coumaric acid, chlorogenic acid, 4-hydroxybenzoic acid, rutin, and kaempferol, and sinapinic acid was positively correlated with quercetin and vanillic acid. Furthermore, quercetin was positively correlated with kaempferol (Figure S3).

A metabolite linkage map was produced based on a total of 44 metabolites identified by GC-TOFMS, and 7 phenolics quantified by HPLC, to investigate metabolic similarities between white and violet flowers of $M$. denudata (Figure 3 and Figure S4). Carbohydrates are molecular compounds consisting of oxygen $(\mathrm{O})$, hydrogen $(\mathrm{H})$, and carbon $(\mathrm{C})$, predominantly used as energy and carbon sources, signaling molecules, osmotic agents, and protectants against certain stressor in plants [30]. In both flowers carbohydrates, including fructose, xylose, glucose, galactose, mannose, sucrose, maltose, trehalose, mannitol, glycerol, and raffinose, were the most abundant metabolites. The total amount of carbohydrates in violet flowers was 1.74-fold higher than that in white flowers, indicating higher energy and carbon demands for the production of phenolic compounds. Specifically, the concentrations of fructose, glucose, mannose, sucrose, maltose, and xylose, were higher in violet flowers. In contrast, the levels of mannitol, raffinose, and trehalose were higher in white flowers (Figure S4). Amino acids are organic nitrogen compounds formed by the assimilation of inorganic nitrogen and binding to a carbon skeleton to produce amino acids such as asparagine, aspartate, glutamine, and glutamate [31]. In the present study, a total of 20 different amino acids was identified in both flowers. The total amino acid concentration in white flowers was, on average, 1.30 times that of violet flowers. Specifically, the individual levels of the amino acids valine, serine, isoleucine, glycine, threonine, phenylalanine, asparagine, glutamine, tryptophan, and aspartate were higher in the white flowers. In contrast, two of the amino acids, 4-Aminobutyric acid, and glutamate, were found in higher concentrations in violet flowers (1.42-fold, and 1.42-fold, respectively). The greater abundance of asparagine (1.27-fold), aspartate (1.60-fold), and glutamine (1.24-fold), which is involved in nitrogen metabolism, in the white flowers reflected the higher levels of other amino acids. Furthermore, a total of four photorespiratory intermediates was identified in both flowers. White flowers, however, contained larger amounts of glycine (1.74-fold) and serine (1.40-fold). White flowers also contained larger amounts of most TCA cycle intermediates, including citrate (1.33-fold), succinate (2.69-fold), and malate (1.40-fold), which were associated with the higher concentrations of higher amino acids, including 
alanine, GABA, aspartate, tyrosine, and asparagine, compared to violet flowers. However, the amount of fumarate was 1.20-fold higher in violet than in white flowers. Regarding phenolic compounds, higher concentrations of phenolics such as chlrogenic acid, caffeic acid, 4-hydroxybenzoic acid, $p$-coumaric acid, rutin, and anthocyanins were found in violet flowers. In contrast, white flowers contained the higher concentration of sinapic acid. Anthocyanin, which is present in higher concentrations in violet flowers, presumably necessitates higher amounts of precursors or intermediates, including $p$-coumaric acid and caffeic acid.

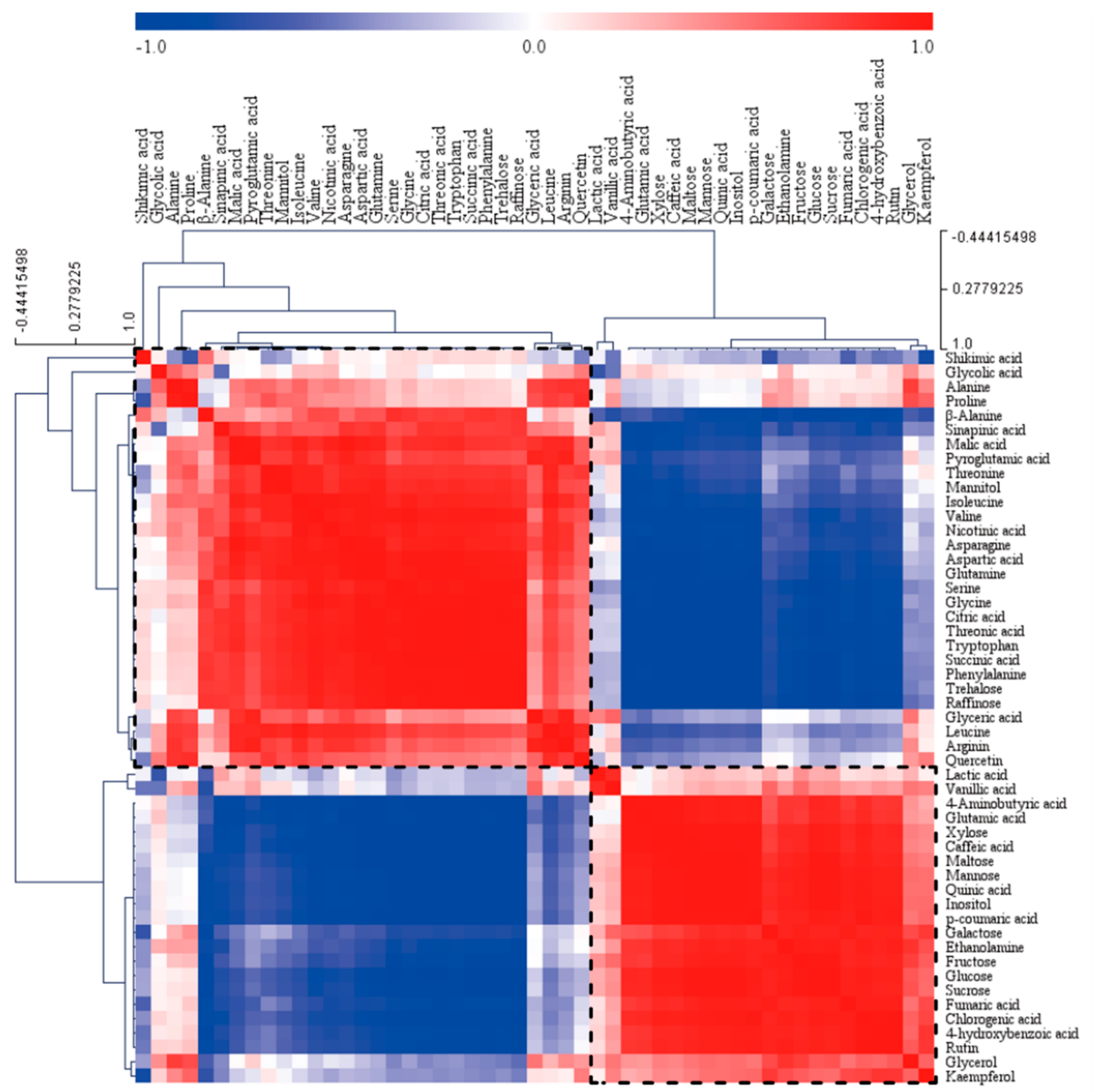

Figure 2. Correlation matrix of 51 metabolites from white flowers of $M$. denudata and violet flowers of M. liliiflora. Each square indicates the Pearson's correlation coefficient of a pair of compounds, with the correlation coefficient indicated by the intensity of the red and blue colors. Dashed-line boxes indicate the 51 metabolites were clustered by an HCA using the Pearson's correlation and average linkage clustering. 


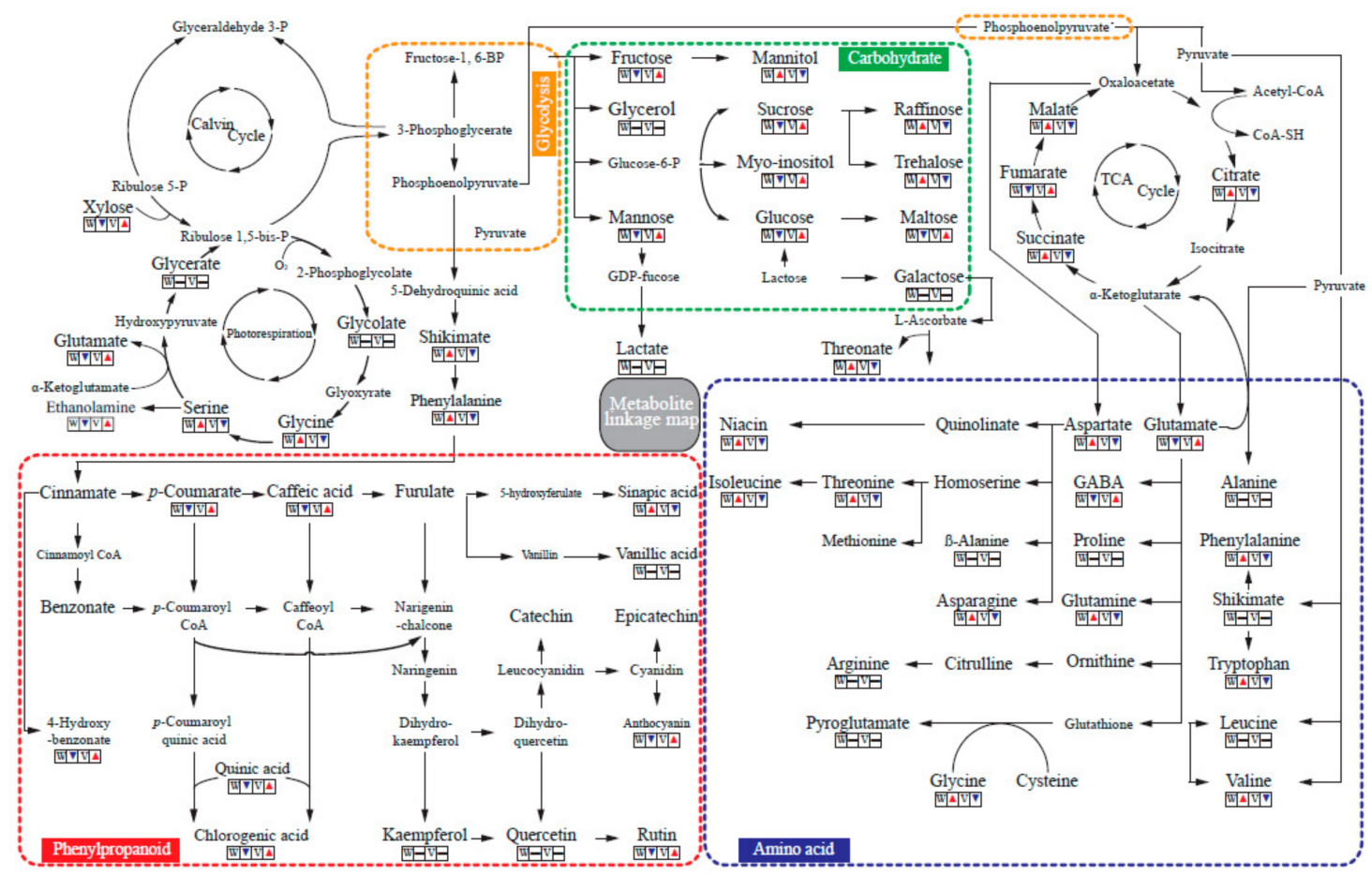

Figure 3. A metabolic linkage map comparing primary and secondary metabolites of white flowers of M. denudata and violet flowers of $M$. liliiflora. The up arrow ( $\mathbf{\Delta})$ indicates a significantly higher mean value of the metabolite (at $p<0.05)$. The down arrow $(\mathbf{\nabla})$ indicates a significantly lower mean value of the metabolite (at $p<0.05$ ). The horizontal bar $(-)$ indicates that no significant difference was found (at $p<0.05)$.

\subsection{In-Vitro Antioxidant Assays}

\subsubsection{1,1-Diphenyl-2-picrylhydrazyl (DPPH) Radical Scavenging Activity}

DPPH radical scavenging activity was measured using ethanol extracts from two different flowers at different concentrations (50 to $250 \mu \mathrm{g} / \mathrm{mL}$; Figure 4A). DPPH scavenging activity depended on the extract concentrations, in both flowers. In particular, the highest DPPH radical scavenging activity was observed in violet flowers (68.45\%) and an extract concentration of $250 \mu \mathrm{g} / \mathrm{mL}$, followed by white flowers $(34.91 \%)$ at the same concentration. Moreover, violet flowers also showed higher radical scavenging activities than white flowers at lower concentrations (100 to $200 \mu \mathrm{g} / \mathrm{mL}$ ). However, at concentrations below $100 \mu \mathrm{g} / \mathrm{mL}$, the enzymatic activities did not differ between flowers. 

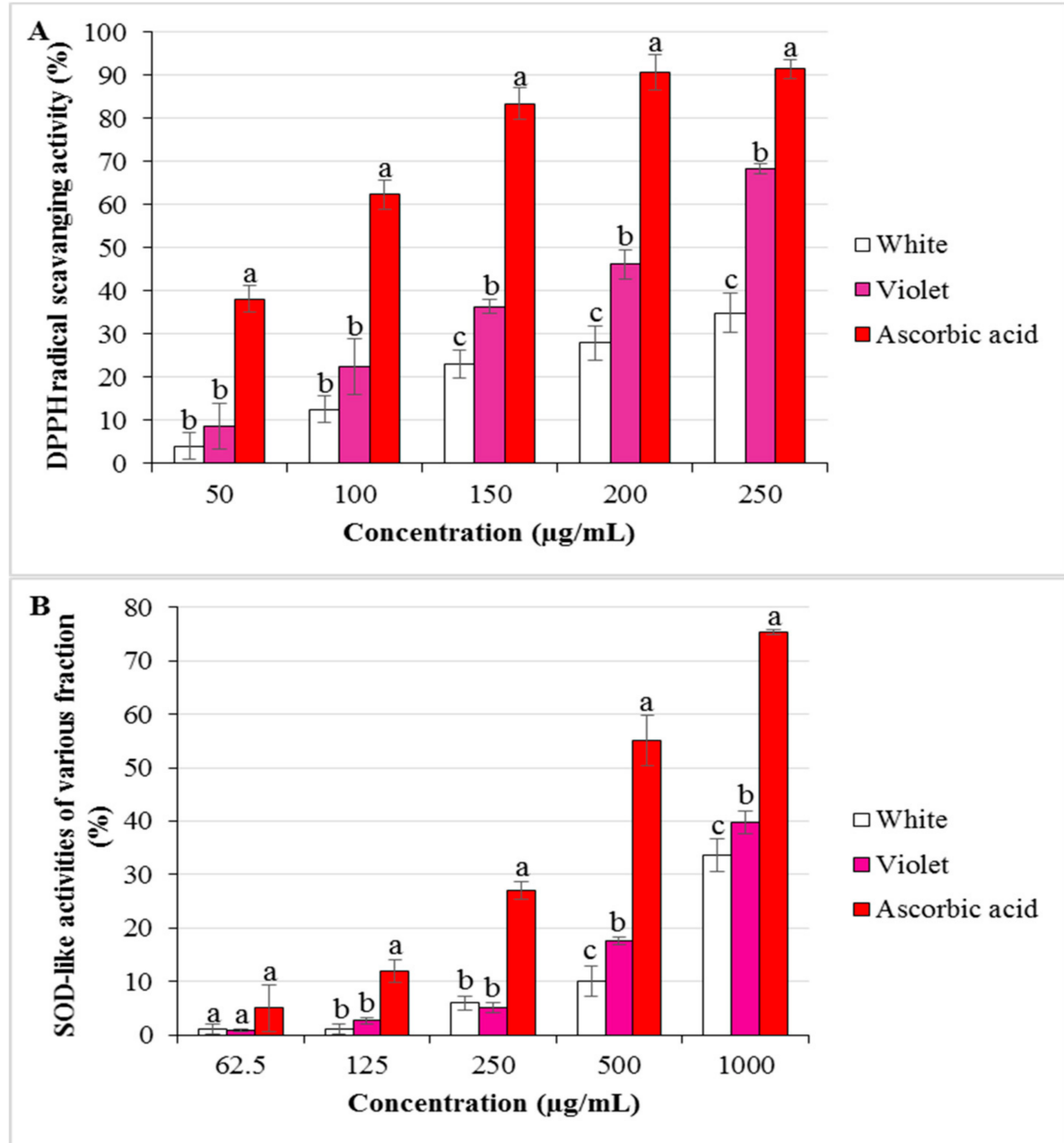

Figure 4. (A) 1,1-Diphenyl-2-picrylhydrazyl (DPPH) radical scavenging activity of ethanol extracts from white and violet flowers. (B) Superoxide radical scavenging activity in ethanol extracts from white and violet flowers, respectively. Shown are the mean values (in per cent) of triplicated experiments \pm standard deviation (SD). Different letters ( $a, b, c$, respectively) indicate a significant difference at $p<0.05$, applying a Duncan's multiple range test.

\subsubsection{Dismutase-Like Activity}

Superoxide dismutase (SOD)-like activity was determined using extracts from two different flowers (at concentrations from 62.5 to $1000 \mu \mathrm{g} / \mathrm{mL}$; Figure 4B). Superoxide radical scavenging activity was higher in violet flowers (39.81\%) than in white flowers (33.59\%), at $1000 \mu \mathrm{g} / \mathrm{mL}$, each. Furthermore, at a lower concentration of $500 \mu \mathrm{g} / \mathrm{L}$, violet flowers showed higher enzymatic activity $(17.57 \%)$ than white flowers (11.51\%). In contrast, at concentrations below $500 \mu \mathrm{g} / \mathrm{mL}$, SOD-like activities did not differ between white and violet flowers.

\subsection{3-(4,5-Dimethylthiazol-2-yl)-2,5-diphenyltetrazolium Bromide (MTT) Assay for Cell Viability}

Cytotoxic effects of ethanol extracts of white and violet flowers, were determined using an MTT assay. Extracts of white and violet flowers at different concentrations (1.953125 to $1000 \mu \mathrm{g} / \mathrm{mL})$ were added to RAW 264.7 cells stimulated by a lipopolysaccharide (LPS) treatment. After an incubation period of $24 \mathrm{~h}$, cells treated with violet flowers at a concentration above $3.90625 \mu \mathrm{g} / \mathrm{mL}$ showed a decrease in viability (Figure S5). In contrast, the white flower treatment only reduced cell viability at extract concentrations above $31.25 \mu \mathrm{g} / \mathrm{mL}$. Therefore, a nitric oxide (NO) assay was performed using extracts of white and violet flowers at concentrations above $3.90625 \mu \mathrm{g} / \mathrm{mL}$. 


\subsection{Nitric Oxide (NO) Assay}

We tested the inhibition of NO accumulation in LPS-activated RAW264.7 cells following treatment with ethanol extracts of white and violet flowers. Cells were treated simultaneously with LPS (500 ng/mL) and ethanol extracts of each flower, at different concentrations (0.625 to $2.5 \mu \mathrm{g} / \mathrm{mL}$ ). The production of NO production was measured as nitrite quantity in the culture medium. In a control experiment, a Dulbecco's Modified Eagle's medium (DMEM) treatment without LPS activation did not lead to NO production, however, NO was produced when cells were simultaneously treated with LPS (500 ng/mL; $1.52 \pm 0.07 ; 1.43 \pm 0.06$, respectively). The violet flower extract (at $2.5 \mu \mathrm{l} / \mathrm{mL})$ significantly inhibited the nitrite production in LPS-activated-RAW 264.7 cells, compared to the control $(p<0.05)$. White flower extract at the same concentration, however, did not inhibit nitrite production (Figure 5).

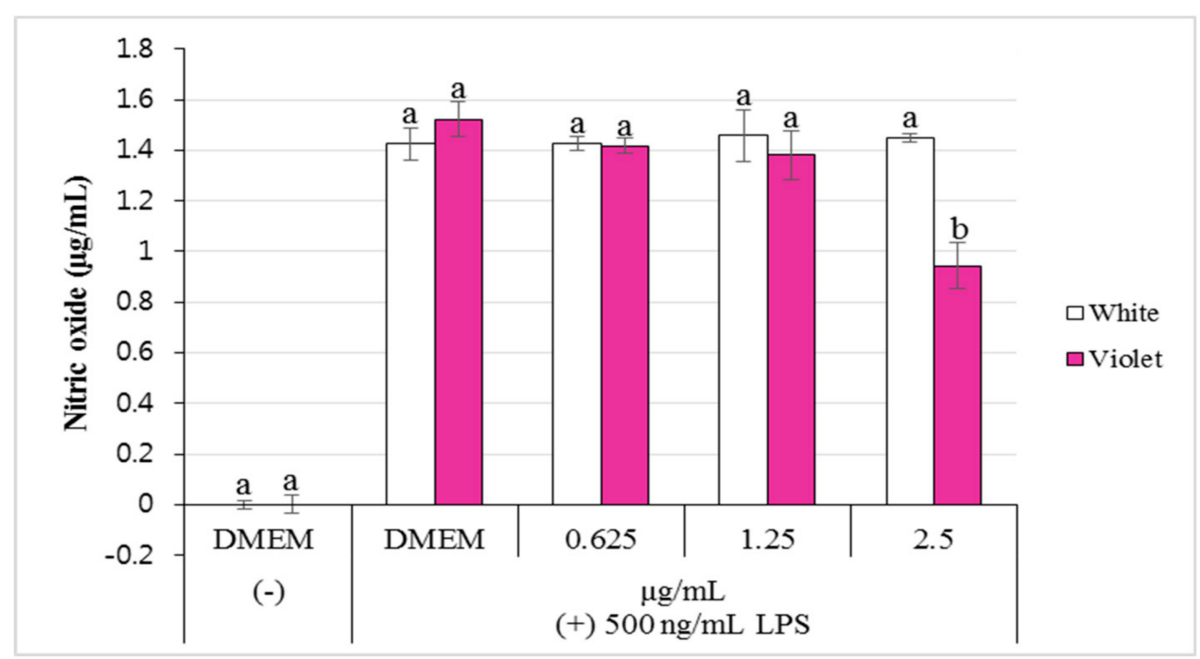

Figure 5. Effect of ethanol extracts from white and violet flowers, respectively, on NO production in LPS-activated RAW264.7 cells. Cells were treated extracts of various concentrations ( 0.625 to $2.5 \mu \mathrm{g} / \mathrm{mL}$ ). The amount of NO in the culture medium was measured using a NO assay. Shown are the mean values (in per cent) of triplicated experiments \pm SD. Different letters $(a, b)$ indicate a significant difference at $p<0.05$, applying a Duncan's Multiple Range Test (DMRT).

In the present study, we found three flavonoids (rutin, quercetin, and kaempferol), and four phenolic acids (4-hydroxybenzoic acid, chlorogenic acid, caffeic acid, $p$-coumaric acid) in white and violet flowers, using LC-MS and HPLC. Previous studies found rutin in flower extracts of Magnolia denudata [32], chlorogenic acid, and coumaric acid in the foliage of Magnolia sieboldii K. Koch [33], and quercetin and rutin in Magnolia obovata leaves [34]. Furthermore, Porter et al. (2015) reported the presence of kaempferol in Magnolia tepals [35]. Among the identified compounds, rutin, which is the most abundant compound, has only recently been introduced in medicinal products and nutritional supplements due to its diverse biological activities, including anti-diabetic, anti-oxidant, anti-inflammatory, and anti-asthmatic properties [36-40]. Similarly, chlorogenic acid, the second most abundant compound, has been widely used in the cosmetic and food processing industries because of physiological effects, e.g. anti-inflammatory, anti-oxidant, and anti-carcinogenic functions [41]. Furthermore, the consumption of quercetin and kaempferol in tea has been shown to enhance antioxidant capacity and to inhibit carcinogen-induced tumors in mice and rats [42]. Therefore, white flowers of $M$. denudata and violet flowers of $M$. liliiflora may be potentially useful raw materials for the production of herbal remedies, food, and cosmetics.

Possible variations between the results reported by the present study and those reported by previous studies are not surprising. This might because ecological factors, including altitude, latitude, longitude, longitude, annual sunshine duration, and annual average temperature, can affect the quality and quantity of phytochemicals [43]. Differences in the extraction methods, solvents, and conditions 
have led to variations in phytochemical composition [44]. Additionally, environmental factors can affect chemical composition [45].

Our results confirm that internal pools of primary metabolites may be correlated with the amounts of secondary metabolites, which is in agreement with the results of a previous study [46]. Carbohydrates play an important role in plant secondary metabolism as metabolic precursors and energy sources. Consistent with the results of the present study, previous studies have shown that the composition and relative concentration of carbon sources affected flavonoid production in callus culture of Hydrocotyle bonariensis [47]. The total concentrations of carbohydrates, including glycerol, fructose, galactose, glucose, mannose, mannitol, sucrose, maltose, trehalose, raffinose, and xylose were higher in violet flowers, than that in white flowers, indicating a higher demand for carbon and energy for the production of phenolic compounds. Furthermore, Pearson's correlation analysis and a HCA showed a significant positive correlation between the concentrations of carbohydrates and phenolic compounds (Figure S2 and Figure 2). Particularly, the higher concentration of sucrose might be required for the higher production of phenolic compounds in violet flowers. Similarly, Zulak et al. (2008) reported that in poppy (Papaver somniferum) cell cultures, supplementation with a fungal elicitor promoted the production of alkaloids and thereby rapidly depleted internal sugar reservoirs [48].

Previously, Payyavula et al. (2013) reported that potatoes with red or purple flesh contained higher content of phenolics and anthocyanins, as well as higher sucrose and glucose content than potatoes with white or yellow flesh. Furthermore, sucrose treatment can significantly increase the expression of the phenylpropanoid-related genes phenylalanine ammonia lase $(P A L)$, chalcone synthase (CHS), flavanone 3-hydroxylase $(F 3 H)$, dihydroflavonol 4-reductase (DFR), UDPG flavonoid O-glucosyltransferase (UFGT), anthocyanin methyltransferase (AOMT3), transcription factors anthocyanin1 (AN1), basic-Helix-Loop-Helix1 (bHLH1), WD40, and the expression of the sugar metabolism-related genes sucrose synthase1 (SUSY1), sucrose synthase4 (SUSY4), and invertase2 (INV2), and increase the amounts of phenolic compounds in potato plantlets [49]. Similarly, an increase in sucrose concentration enhances cell growth and phenylpropanoid production in grapevine cell cultures, with the phenylpropanoid production partly correlated with the expression of the phenylpropanoid-related genes PAL, CHS, and chalcone-flavanone isomerase (CHI) [50]. Park et al. (2016) reported that the exogenous sucrose supply to hairy root cultures of Scutellaria baicalensis enhanced the production of flavonoids, such as wogonin, baicalin, and baicalein [51].

In our study, we identified bioactive compounds, such as rutin, quercetin, kaempferol, 4-hydroxybenzoic acid, chlorogenic acid, caffeic acid, $p$-coumaric acid, sinapic acid, quinic acid, and vanillic acid by HPLC and GC-TOFMS. Phenolics, including phenolic acids and flavonoids, are considered natural antioxidants due to their ability to donate electrons to oxidative molecules [52,53]. Among the identified flavonoids, rutin, quercetin, and kaempferol have been shown to be potential antioxidants [54]. Comparably, hydrocinnamic acids (chlorogenic acid, caffeic acid, $p$-coumaric acid, sinapic acid) and hydroxybenzoic acids (4-hydroxybenzoic acid, vanillic acid) are known for their antioxidative potential as well $[55,56]$. Anthocyanins, which belong to the class of flavonoids, are strong natural antioxidants [57]. The present study demonstrates that higher scavenging activities and anti-inflammatory activity can be observed in violet flowers compared to white flowers, using DPPH, SOD-like, and NO activity assays. These antioxidative properties may be due to the higher concentrations of phenolic compounds (which are also natural antioxidants) in violet flowers. The findings are consistent with a previous study reporting that in radish (Raphanus sativus), the red variety showed higher antioxidant activity than white radish [58]. Moreover, in lettuce (Lactuca sativa), red varieties also contain higher amounts of total phenolics, flavonoids, anthocyanins, and carotenoids, and thus also showed higher antioxidant activities than green lettuce [59].

According to the World Health Organization (WHO), approximately $80 \%$ of the global population depends on medicinal plants for their primary healthcare needs $[60,61]$. Thus, the present study provides evidence for the potential of various applications of white flowers of $M$. denudata and violet 
flowers of $M$. liliiflora in herbal medicine. Furthermore, further studies should investigate identification of the unknown compound.

\section{Materials and Methods}

\subsection{Plant Materials}

Ten grams of white flowers of $M$. denudata and violet flowers of $M$. liliiflora were harvested in triplicate from the experimental plantation of Chungnam National University in March 2018, and were immediately submerged in liquid nitrogen $\left(-196^{\circ} \mathrm{C}\right)$. Subsequently, flower samples were freeze-dried at $-80^{\circ} \mathrm{C}$ for three days, and then ground by hand into a fine powder, using mortar and pestle.

\subsection{LC-MS Analysis for the Quantification of Phenylpropanoid Contents}

For the LC-MS of white flowers of M. denudata, an Agilent 1200 series HPLC device (Agilent Technologies, Palo Alto, CA, USA) coupled to a model G1315D diode array detector (DAD), and a 4000 Qtrap LC/MS/MS system (Applied Biosystems Instrument, Foster City, CA, USA) using the negative ion mode $\left([\mathrm{M}-\mathrm{H}]^{-}\right)$. The LC-MS conditions were set as follows: scan time of $4.80 \mathrm{~s}$; scan range from 100 to $1300 \mathrm{~m} / z$; curtain gas $\left(\mathrm{N}_{2}\right)$ at 20.00 psi; nebulizer gas at 50 psi; drying gas at $50 \mathrm{psi}$; drying gas temperature of $550{ }^{\circ} \mathrm{C}$; entrance potential of $10 \mathrm{~V}$; declustering potential of $100 \mathrm{~V}$; and ionization voltage of $5000 \mathrm{~V}$.

\subsection{Phenylpropanoid HPLC Analysis}

Phenylpropanoid extraction and HPLC analysis were performed for both flower types, according to the method described by Park et al. (2017) [62]. A total of $0.1 \mathrm{~g}$ of the sample material was aliquoted into a $15 \mathrm{~mL}$ tube, and $2 \mathrm{~mL}$ of methanol $(80 \% v / v)$ was added. Subsequently, the tube was sonicated for $1 \mathrm{~h}$ at $35{ }^{\circ} \mathrm{C}$, and then centrifuged at $4000 \mathrm{rpm}$ for $10 \mathrm{~min}$. The supernatant was collected in a new tube. This procedure was also applied to the remaining sample material. The collected products were dried under nitrogen gas, and subsequently resuspended in $2 \mathrm{~mL}$ of methanol. The HPLC analysis system, condition, and gradient program were performed as detailed in a previous study [62]. The separting solvent consisted of a mixture of solvent A (acetic acid/water $(0.2: 99.8, v / v)$ ), and solvent B (methanol). Samples were eluted with the following gradient condtions: $0 \mathrm{~min}, 95 \%$ A; $4 \mathrm{~min}, 95 \%-85 \%$ A; $9 \mathrm{~min}$, 85\% A; $14 \mathrm{~min}, 85 \%-80 \%$ A; $24 \mathrm{~min}, 80 \%$ A; $54 \mathrm{~min}, 80 \%-70 \%$ A; $55 \mathrm{~min}, 70 \%-55 \%$ A; $65 \mathrm{~min}, 55 \%$ A; $75 \mathrm{~min}, 55 \%-44 \%$ A; $77.0 \mathrm{~min}, 44 \%-40 \%$ A; $79 \mathrm{~min}, 40 \%$ A; $80 \mathrm{~min}, 40 \%-20 \%$ A; $90 \mathrm{~min}, 20 \%$ A; $91.0 \mathrm{~min}, 20 \%-95 \% \mathrm{~A}$; and $98.0 \mathrm{~min}, 95 \% \mathrm{~A}$. The detection wavelength and oven temperature set at $280 \mathrm{~nm}$ and $40{ }^{\circ} \mathrm{C}$. The flow rate and injection volume were $1.0 \mathrm{~mL} / \mathrm{min}$ and $20 \mu \mathrm{L}$, respectively. Comparison of retention times and spiking tests were used to identify each peak. Quantitation was performed using the respective calibration curves. The HPLC data was analyzed using SAS software (version 9.4, 2013; SAS Institute, Inc., Cary, NC, USA), applying an Analysis of Variance (ANOVA) evaluation and a Duncan's Multiple Range Test (DMRT). The level of statistical significance was set at $p<0.05$.

\subsection{Total Phenolics}

Powdered sample material $(200 \mathrm{mg})$ of white and violet flowers, respectively, was extracted with $2 \mathrm{~mL}$ of ethanol and sonicated for $2 \mathrm{~h}$. After an incubation period of $24 \mathrm{~h}$, the extracts were centrifuged at 10,000 rpm for $15 \mathrm{~min}$, and subsequently filtered through a $0.45 \mu \mathrm{m}$ polyterafluoroethylene (PTFE) hydrophilic syringe filter into a vial. The extracts were then prepared for measuring total phenolic and anthocyanin content. The Folin-Ciocalteu method was used for the quantification of total phenolic content [58]. A total of $100 \mu \mathrm{L}$ of extract was added to a $15-\mathrm{mL}$ tube containing $3.4 \mathrm{~mL}$ of deionized water (DW) and $0.5 \mathrm{~mL}$ of $2 \mathrm{~N}$ Folin \& Ciocalteu's phenol reagent (Sigma-Aldrich, Yongin, Korea). After incubation for $3 \mathrm{~min}$ at $28{ }^{\circ} \mathrm{C}, 2 \mathrm{~mL}$ of sodium carbonate $(20 \%, w / v)$ was added to the mixture, which was then incubated for $1 \mathrm{~h}$ in the dark. The absorbance of each sample was measured at $760 \mathrm{~nm}$ 
in a standard spectrophotometer (UV). A calibration curve equivalent (standard curve equation: $\left.y=0.001981712 x+0.032496678, R^{2}=0.997201606\right)$ was created using different concentrations $(10,60$, $100,200,400,600,800$, and $1000 \mu \mathrm{g} / \mathrm{mL}$ ) of a gallic acid standard. The final results are presented as milligrams of gallic acid equivalent per gram of dry weight (mg GAE/g dry weight).

\subsection{Total Anthocyanin Content}

The $\mathrm{pH}$ differential method, consisting of $\mathrm{KCl}$ buffer $(0.025 \mathrm{M}, \mathrm{pH} 1.0)$ and $\mathrm{CH}_{3} \mathrm{COONa}_{\text {buffer }}$ (0.4 M, pH 4.5), was used to measure the total anthocyanin content in the prepared crude extract of each sample [59]. Aliquots of $1 \mathrm{~mL}$ of the extract were mixed with $4 \mathrm{~mL}$ of each of the buffers, and incubated at $28^{\circ} \mathrm{C}$ for $15 \mathrm{~min}$ for equilibration. The absorbance reading was performed at 510 and $700 \mathrm{~nm}$ against DW as a blank control. The absorbance (A) of each sample was calculated with the following equation: $\mathrm{A}=[(\mathrm{A} 510-\mathrm{A} 700) \mathrm{pH} 1.0-(\mathrm{A} 510-\mathrm{A} 700) \mathrm{pH} 4.5]$. The total anthocyanin concentration $(\%, w / w)$ was then determined using the following formula: monomeric anthocyanin pigment $(\mathrm{mg} / \mathrm{L})=(\mathrm{A} \times \mathrm{MW} \times \mathrm{DF} \times 1000) /(\varepsilon \times 1)$; where the molecular weight $(\mathrm{MW})=449.2 \mathrm{~g} \cdot \mathrm{mol}^{-1}$, and the extinction coefficient $\varepsilon=26,900 \mathrm{M}$ in $\mathrm{L} \mathrm{mol} \mathrm{mom}^{-1}$ of cyanidin-3-glucoside; the factor 1000 converts $\mathrm{g}$ to $\mathrm{mg}$; DF indicates the dilution factor; 1 indicates the cuvette pathlength. The final results were converted to milligrams of cyanidin-3-glucoside equivalents per gram dry weight (mg CGE/g dry weight).

\subsection{GC-TOFMS Analysis}

The extraction method described by Li et al. (2014) [63] was used to measure hydrophilic metabolite contents in white and violet flowers. To $10 \mathrm{mg}$ powdered samples we added $1 \mathrm{~mL}$ of a water-chloroform-methanol solution $(1: 1: 2.5 \mathrm{v} / \mathrm{v} / \mathrm{v})$, then $60 \mu \mathrm{L}$ of ribitol $(0.2 \mathrm{mg} / \mathrm{mL})$ was added as an internal standard (IS). The mixture was incubated and mixed in a compact thermomixer at $1200 \mathrm{rpm}$ and $37^{\circ} \mathrm{C}$ for $30 \mathrm{~min}$, followed by centrifugation at $9000 \mathrm{rpm}$ for $10 \mathrm{~min}$. Subsequently, $0.8 \mathrm{~mL}$ of the polar phase was moved into a new $2 \mathrm{~mL}$ tube containing $0.4 \mathrm{~mL}$ of deionized water. This mixture was again centrifuged at $9000 \mathrm{rpm}$ for $5 \mathrm{~min}$. A CVE-2000 centrifugal concentrator (Eyela, Japan) and a FD8512 freeze-dryer (Ilshin Lab Co., Ltd., Dongducheon, Korea) were used to facilitate evaporation of the methanol-water phase. The residues, containing hydrophilic metabolites were subjected to a two-stage process, methoxime derivatization and trimethylsilyl etherification. A total of $80 \mu \mathrm{L}$ of methoxyamine hydrochloride in pyridine $(20 \mathrm{mg} / \mathrm{mL})$ was added to each sample, which was then incubated under constant shaking at $30^{\circ} \mathrm{C}$ for $90 \mathrm{~min}$. Then, $80 \mu \mathrm{L}$ of $N$-methyl- $N$-(trimethylsilyl)trifluoroacetamide was added, followed by another incubation period at $37^{\circ} \mathrm{C}$ for $30 \mathrm{~min}$. GC-TOFMS analysis was carried out exactly as descried by Li et al., 2014 [63]. The split ratio was set at 1:25. The injector temperature and flow rate of helium through the column were $230^{\circ} \mathrm{C}$ and $1.0 \mathrm{~mL} / \mathrm{min}$, respectively.The temperature program was established as follows: initial temperature of $80^{\circ} \mathrm{C}$ for $2 \mathrm{~min}$, followed by an increase to $320^{\circ} \mathrm{C}$ at $15^{\circ} \mathrm{C} / \mathrm{min}$, and a $10 \mathrm{~min}$ hold at $320^{\circ} \mathrm{C}$. The ion-source temperatures were set at $200{ }^{\circ} \mathrm{C}$, and the transfer line was 250 . The detector voltage and scanned mass range were $1700 \mathrm{~V}$. T and $85-600 \mathrm{~m} / \mathrm{z}$, respectively. The quantitaion of each analyte was based on the peak area ratio relative to that of the IS (Figure S6 and Table S1). The GC-TOFMS analysis was performed in three technical replicates. A Statistical Analysis System software (SAS, system 9.4, 2013; SAS Institute, Inc., Cary, NC, USA) and Multi Experiment Viewer (version 4.4.0, Dana-Farber Cancer Institute, Boston, MA, USA, http: / / www.tm4.org/mev/) were used for the analysis of the GC-TOFMS raw data. A principal component analyses (PCA) was performed on the correlation matrices and represented mean \pm standard deviation of the technical replicates.

\subsection{Superoxide Dismutase (SOD)-Like Activity}

SOD-like activity of extracts of white and violet flowers was evaluated as previously described [64]. A total of $100 \mu \mathrm{L}$ of the extract solution $(62.5-1000 \mu \mathrm{g} / \mathrm{mL})$ was placed in a test tube. To this, $120 \mu \mathrm{L}$ of $50 \mathrm{mM}$ Tris- $\mathrm{HCl}$ buffer ( $\mathrm{pH} 8.5$ ) and $20 \mu \mathrm{L}$ of $7.2 \mathrm{mM}$ pyrogallol solution were added, followed 
by incubation at $25{ }^{\circ} \mathrm{C}$ for $10 \mathrm{~min}$. Then, $40 \mu \mathrm{L}$ of hydroxylamine hydrochloride $(1 \mathrm{M})$ was added to stop the reaction. The absorbance was measured at $420 \mathrm{~nm}$ using a standard UV spectrophotometer. A blank control containing distilled water instead of sample extracts was used, and ascorbic acid was used as a standard.

The following formula was applied: Superoxide dismutase-like activity $(\%)=[(1-\mathrm{A} 1) / \mathrm{A} 0] \times 100$, where $\mathrm{A} 0$ is the absorbance of the control, and $\mathrm{A} 1$ is the absorbance of the sample. All samples were analyzed in three technical replicates.

\subsection{DPPH Assay}

DPPH radical scavenging activity in extracts of different colored flowers was measured according to the method described in Park et al. (2018) [59]. A total of $100 \mu \mathrm{L}$ of extract solution $(62.5-1000 \mu \mathrm{g} / \mathrm{mL})$ was placed in a test tube. To this, $100 \mu \mathrm{L}$ of $1 \mathrm{mM}$ DPPH was added, following incubation at $25^{\circ} \mathrm{C}$ for $10 \mathrm{~min}$ in the dark. The absorbance was read at $520 \mathrm{~nm}$ using a UV spectrophotometer. A blank control containing distilled water instead of sample extracts was used, and ascorbic acid was used as a standard. The following formula was used: DPPH radical scavenging activity $(\%)=[(1-\mathrm{A} 1) / \mathrm{A} 0] \times 100$, where $\mathrm{A} 0$ is the absorbance of the control and $\mathrm{A} 1$ is the absorbance of the sample. All samples were analyzed in three technical replicates.

\subsection{MTT Assay for Cell Viability}

A MTT assay was performed as described previously [65]. RAW 264.7 cells $\left(3 \times 10^{4}\right.$ cells $/$ well $)$ were plated in 96-well plates and cultured for $24 \mathrm{~h}$, followed by supplementation with LPS $(50 \mathrm{ng} / \mathrm{mL})$ and ethanol extracts at different concentrations $(1.953125-15.625 \mu \mathrm{g} / \mathrm{mL})$. After the second incubation period of $24 \mathrm{~h}, 10 \mu \mathrm{L}$ of MTT were supplemented to the medium, and cells were again and cultured for $4 \mathrm{~h}$. After this, the supernatant was discarded and the dimethyl sulfoxide was used for the dissolution of the emerged formazan crystals. Absorbance was measured at $540 \mathrm{~nm}$. The percentage of dead cells was measured relative to the control sample, which was a treatment with DMEM, instead of LPS or ethanol extracts. Nitrite quantity was determined using a sodium nitrite standard curve.

\subsection{Nitric Oxide (NO) Assay}

An NO assay was performed as described previously [65]. RAW 264.7 cells were cultured in a modification of Eagle's medium after Dulbecco, and supplemented with $1 \%$ antibiotic-antimycotic and $10 \%$ fetal bovine serum, under $5 \% \mathrm{CO}_{2}$ at $37^{\circ} \mathrm{C}$. To investigate the effect of crude extracts of white and violet flowers, on NO production, cells were loaded onto 96-well plates $\left(3 \times 10^{4}\right.$ cells /well) using fresh culture medium, and were then pre-incubated for $2 \mathrm{~h}$. After this, LPS (50 ng/mL) and sample extracts $(62.5-1000 \mu \mathrm{g} / \mathrm{mL})$ were added, followed by another incubation period of $24 \mathrm{~h}$. Subsequently, the nitrite quantity was measured as an indicator of NO production. In brief, $100 \mu \mathrm{L}$ of Griess reagent ( $0.1 \% \mathrm{~N}$-(1-naphthyl) ethylenediamine dihydrochloride and $1 \%$ sulfanilamide in $2.5 \%$ phosphoric acid) was added to $100 \mu \mathrm{L}$ of cell culture medium. Then, the mixture was incubated for $10 \mathrm{~min}$ at room temperature, after which absorbance was measured at $540 \mathrm{~nm}$ using a microplate reader. Fresh medium was used as a blank control in every experiment. The amount of nitrite was determined using a sodium nitrite standard curve.

\subsection{Statistical Analysis}

Data from GC-TOFMS and HPLC were analyzed using Statistical Analysis System (SAS, system 9.4, 2013; SAS Institute, Inc., Cary, NC, USA); SIMCA-P (version 12.0, Umetrics, Umeå, Sweden), and Multi Experiment Viewer (version 4.4.0, Dana-Farber Cancer Institute, Boston, MA, USA, http:/ /www.tm4.org/mev/) software. Results are presented as mean \pm standard deviation of three technical replicates. Data obtained from GC-TOFMS was scaled to unit variance scaling and then subjected to partial least-squares discriminant analysis (PLS-DA) using SIMCA-P software (version 12.0, Umetrics, Umeå, Sweden) to determine differences in metabolite profiles between the 
varieties. The PLS-DA output is presented as score plot to demonstrate contrasts. Furthermore, Pearson's correlation analysis was performed based on the relative concentrations of 42 metabolites applying a standardization procedure in SAS 9.4. The resulting correlation coefficients were visualized by a hierarchical clustering analysis (HCA), and a heat map which was produced from the Multi Experiment Viewer, and Duncan's multiple range test (DMRT, $p<0.05)$ was performed to depict a metabolic linkage map.

\section{Conclusions}

Here, we report the relationship between primary and secondary metabolites in the different colored Magnolia flowers. Violet flowers contained higher concentrations of phenolic compounds and of carbohydrates, compared to white flowers. This may reflect the higher carbon and energy demand for the synthesis of phenylpropanoids. The higher amounts of phenolic compounds in violet flowers may partially explain higher radical scavenging activity and anti-inflammatory properties. Correspondingly, our results confirm that HPLC- and GC-TOFMS-based metabolomic profiling are suitable methods to determine the interplay between primary and secondary metabolites in $M$. denudata and M. liliiflora flowers.

Supplementary Materials: The following are available online. Figure S1: LC-MS spectrum of phenolic compounds identified in white flowers of Magnolia denudata Desr. 1,4-hydroxybenzoic acid; 2, Chlorogenic acid; 3, Caffeic acid; 4, p-coumaric acid; 5, Rutin; 6, Quercetin; 7, Kaempferol. Figure S2: Scores and loading plots of principal components 1 and 2 of the PCA results obtained from polar metabolite data of white flowers of M. denudata and violet flowers of M. liliiflora. 1-44, the compounds listed in Table S1. Figure S3: Correlation matrix of 10 phenolics from white flowers of M. denudata and violet flowers of M. liliiflora. Each square indicates the Pearson's correlation coefficient of a pair of compounds, with the correlation coefficient indicated by the intensity of the red and blue colors. Figure S4: Metabolite peak height differences of white flowers of Magnolia denudata and violet flowers of Magnolia liliiflora based on Duncan's Multiple Range Test $(p<0.05)$ using GC-TOFMS. Figure S5: Effect of ethanol extracts from white and violet flowers, respectively, on the viability of RAW 264.7 cells. Cells were treated with different concentrations ( 1.953125 to $1000 \mu \mathrm{g} / \mathrm{mL})$ of extracts of white and violet flowers. Cell viability was measured by an MTT assay. Figure S6: Selected ion chromatograms of hydrophilic metabolites extracted white flowers of Magnolia denudata as MO/TMS derivatives separated on a $30 \mathrm{~m} \times 0.25 \mathrm{~mm}$ i.d. fused silica capillary column coated with $0.25 \mu \mathrm{m}$ CP-SIL 8 CB low bleed. The numbers represent the same compounds as for Table 1. Table S1: Metabolites identified in GC-TOFMS chromatograms of white flowers of Magnolia denudata.

Author Contributions: S.U.P. and J.K.K. designed the experiments and analyzed the data. C.H.P., S.Y.P. and S.Y.L. performed the experiments and analyzed the data. C.H.P. wrote the manuscript. All authors read and approved the final manuscript.

Acknowledgments: This work was supported by the Incheon National University Research Grant in 2017.

Conflicts of Interest: The authors declare no conflict of interest.

\section{References}

1. Sowndhararajan, K.; Cho, H.; Yu, B.; Kim, S. Comparison of essential oil compositions of fresh and dried fruits of Magnolia kobus DC. J. Appl. Pharm. Sci. 2016, 6, 146-149. [CrossRef]

2. Azuma, H.; Toyota, M.; Asakawa, Y. Intraspecific variation of floral scent chemistry in Magnolia kobus DC. (Magnoliaceae). J. Plant Res. 2001, 114, 411-422. [CrossRef]

3. Seo, J.-J.; Lee, S.-H.; Lee, Y.-S.; Kwon, B.-M.; Ma, Y.; Hwang, B.-Y.; Hong, J.-T.; Oh, K.-W. Anxiolytic-like effects of obovatol isolated from Magnolia obovata: Involvement of GABA/benzodiazepine receptors complex. Prog. Neuro-Psychopharmacol. Biol. Psychiatry 2007, 31, 1363-1369. [CrossRef] [PubMed]

4. Lee, Y.-J.; Lee, Y.M.; Lee, C.-K.; Jung, J.K.; Han, S.B.; Hong, J.T. Therapeutic applications of compounds in the Magnolia family. Pharmacol. Ther. 2011, 130, 157-176. [CrossRef] [PubMed]

5. Teng, C.M.; Chen, C.C.; Ko, F.N.; Lee, L.G.; Huang, T.F.; Chen, Y.P.; Hsu, H.Y. Two antiplatelet agents from Magnolia officinalis. Thromb. Res. 1988, 50, 757-765. [CrossRef]

6. Kassuya, C.A.L.; Cremoneze, A.; Barros, L.F.L.; Simas, A.S.; da Rocha Lapa, F.; Mello-Silva, R.; Stefanello, M.É.A.; Zampronio, A.R. Antipyretic and anti-inflammatory properties of the ethanolic extract, dichloromethane fraction and costunolide from Magnolia ovata (Magnoliaceae). J. Ethnopharmacol. 2009, 124, 369-376. [CrossRef] [PubMed] 
7. Han, X.; Pang, Y.; Liu, S.; Tan, Z.; Tang, S.; Zhou, C.; Wang, M.; Xiao, W. Antidiarrhea and antioxidant activities of honokiol extract from magnoliae officinalis cortex in mice. Trop. J. Pharm. Res. 2014, 13, 1643-1651. [CrossRef]

8. Watanabe, K. Pharmacology of magnolia bark with special reference to gastrointestinal functions. Gendai Toyo Igaku 1986, 7, 54-59.

9. Hamasaki, Y.; Kobayashi, I.; Zaitu, M.; Tsuji, K.; Kita, M.; Hayasaki, R.; Muro, E.; Yamamoto, S.; Matsuo, M.; Ichimaru, T. Magnolol inhibits leukotriene synthesis in rat basophilic leukemia-2H3 cells. Planta Med. 1999, 65, 222-226. [CrossRef] [PubMed]

10. Jo, Y.-H.; Seo, G.-U.; Yuk, H.-G.; Lee, S.-C. Antioxidant and tyrosinase inhibitory activities of methanol extracts from Magnolia denudata and Magnolia denudata var. purpurascens flowers. Food Res. Int. 2012, 47, 197-200. [CrossRef]

11. Li, J.; Tanaka, M.; Kurasawa, K.; Ikeda, T.; Nohara, T. Lignan and neolignan derivatives from Magnolia denudata. Chem. Pharm. Bull. 2005, 53, 235-237. [CrossRef] [PubMed]

12. Jiang, Y.H.; Jiang, X.L.; Cai, C.G. Extraction technology and determination of total flavonoid in Magnolia liliiflora petals. Adv. Mater. Res. 2014, 941-944, 1003-1007. [CrossRef]

13. Vinson, J.A.; Dabbagh, Y.A.; Serry, M.M.; Jang, J. Plant flavonoids, especially tea flavonols, are powerful antioxidants using an in vitro oxidation model for heart disease. J. Agric. Food Chem. 1995, 43, 2800-2802. [CrossRef]

14. Dixon, R.A.; Paiva, N.L. Stress-induced phenylpropanoid metabolism. Plant Cell 1995, 7, $1085-1097$. [CrossRef] [PubMed]

15. Winkel-Shirley, B. Flavonoid biosynthesis. A colorful model for genetics, biochemistry, cell biology, and biotechnology. Plant Physiol. 2001, 126, 485-493. [CrossRef] [PubMed]

16. Tattini, M.; Galardi, C.; Pinelli, P.; Massai, R.; Remorini, D.; Agati, G. Differential accumulation of flavonoids and hydroxycinnamates in leaves of Ligustrum vulgare under excess light and drought stress. New Phytol. 2004, 163, 547-561. [CrossRef]

17. Tanaka, Y.; Sasaki, N.; Ohmiya, A. Biosynthesis of plant pigments: Anthocyanins, betalains and carotenoids. Plant J. 2008, 54, 733-749. [CrossRef] [PubMed]

18. Castaneda-Ovando, A.; de Lourdes Pacheco-Hernández, M.; Páez-Hernández, M.E.; Rodríguez, J.A.; Galán-Vidal, C.A. Chemical studies of anthocyanins: A review. Food Chem. 2009, 113, 859-871. [CrossRef]

19. Clifford, M.N. Anthocyanins-nature, occurrence and dietary burden. J. Sci. Food Agric. 2000, 80, $1063-1072$. [CrossRef]

20. Nijveldt, R.J.; Van Nood, E.; Van Hoorn, D.E.; Boelens, P.G.; Van Norren, K.; Van Leeuwen, P.A. Flavonoids: A review of probable mechanisms of action and potential applications. Am. J. Clin. Nutr. 2001, 74, 418-425. [CrossRef] [PubMed]

21. Guardia, T.; Rotelli, A.E.; Juarez, A.O.; Pelzer, L.E. Anti-inflammatory properties of plant flavonoids. Effects of rutin, quercetin and hesperidin on adjuvant arthritis in rat. Farmaco 2001, 56, 683-687. [CrossRef]

22. Villas-Boas, S.G.; Nielsen, J.; Smedsgaard, J.; Hansen, M.A.; Roessner-Tunali, U. Metabolome Analysis: An Introduction, 1st ed.; JohnWiley \& Sons: Hoboken, NJ, USA, 2007; pp. 1-319.

23. Roessner, U.; Luedemann, A.; Brust, D.; Fiehn, O.; Linke, T.; Willmitzer, L.; Fernie, A.R. Metabolic profiling allows comprehensive phenotyping of genetically or environmentally modified plant systems. Plant Cell 2001, 13, 11-29. [CrossRef] [PubMed]

24. Lu, H.; Liang, Y.; Dunn, W.B.; Shen, H.; Kell, D.B. Comparative evaluation of software for deconvolution of metabolomics data based on GC-TOF-MS. TrAC Trends Anal. Chem. 2008, 27, 215-227. [CrossRef]

25. Dunn, W.B.; Broadhurst, D.; Ellis, D.I.; Brown, M.; Halsall, A.; O’hagan, S.; Spasic, I.; Tseng, A.; Kell, D.B. A GC-TOF-MS study of the stability of serum and urine metabolomes during the UK Biobank sample collection and preparation protocols. Int. J. Epidemiol. 2008, 37, i23-i30. [CrossRef] [PubMed]

26. Becker, S.; Kortz, L.; Helmschrodt, C.; Thiery, J.; Ceglarek, U. LC-MS-based metabolomics in the clinical laboratory. J. Chromatogr. B 2012, 883, 68-75. [CrossRef] [PubMed]

27. Lu, N.; Chen, J.-H.; Wei, D.; Chen, F.; Chen, G. Global metabolic regulation of the snow alga Chlamydomonas nivalis in response to nitrate or phosphate deprivation by a metabolome profile analysis. Int. J. Mol. Sci. 2016, 17. [CrossRef] [PubMed]

28. Lei, Z.; Huhman, D.V.; Sumner, L.W. Mass spectrometry strategies in metabolomics. J. Biol. Chem. 2011, 286, 25435-25442. [CrossRef] [PubMed] 
29. Merly, L.; Smith, S.L. Murine RAW 264.7 cell line as an immune target: Are we missing something? Immunopharmacol. Immunotoxicol. 2017, 39, 55-58. [CrossRef] [PubMed]

30. Lipavská, H.E.L.E.N.; Konrádová, H.A.N. Invited review: Somatic embryogenesis in conifers: The role of carbohydrate metabolism. In Vitro Cell. Dev. Biol. Plant 2004, 40, 23-30. [CrossRef]

31. Lam, H.-M.; Coschigano, K.; Oliveira, I.; Melo-Oliveira, R.; Coruzzi, G. The molecular-genetics of nitrogen assimilation into amino acids in higher plants. Annu. Rev. Plant Biol. 1996, 47, 569-593. [CrossRef] [PubMed]

32. Yoon, H. Effects of aging on the phenolic content and antioxidant activities of magnolia (Magnolia denudata) flower extracts. Food Sci. Biotechnol. 2014, 23, 1715-1718. [CrossRef]

33. Hongbing, G.; Huan, W.; Fengguo, D. Determination of free phenolics and combined phenolics in foliage of Magnolia sieboldii K. Koch. Funct. Mater. 2016, 23, 437-442. [CrossRef]

34. Pyo, M.-K.; Koo, Y.-K.; YunChoi, H.-S. Anti-platelet effect of the phenolic constituents isolated from the leaves of Magnolia obovata. Nat. Prod. Sci. 2002, 8, 147-151.

35. Porter, E.A.; Kite, G.C.; Veitch, N.C.; Geoghegan, I.A.; Larsson, S.; Simmonds, M.S. Phenylethanoid glycosides in tepals of Magnolia salicifolia and their occurrence in flowers of Magnoliaceae. Phytochemistry 2015, 117, 185-193. [CrossRef] [PubMed]

36. Chua, L.S. A review on plant-based rutin extraction methods and its pharmacological activities. J. Ethnopharmacol. 2013, 150, 805-817. [CrossRef] [PubMed]

37. Choi, I.; Park, Y.; Choi, H.; Lee, E.H. Anti-adipogenic activity of rutin in 3T3-L1 cells and mice fed with high-fat diet. BioFactors 2006, 26, 273-281. [CrossRef] [PubMed]

38. Kessler, M.; Ubeaud, G.; Jung, L. Anti-and pro-oxidant activity of rutin and quercetin derivatives. J. Pharm. Pharmacol. 2003, 55, 131-142. [CrossRef] [PubMed]

39. Selloum, L.; Bouriche, H.; Tigrine, C.; Boudoukha, C. Anti-inflammatory effect of rutin on rat paw oedema, and on neutrophils chemotaxis and degranulation. Exp. Toxicol. Pathol. 2003, 54, 313-318. [CrossRef] [PubMed]

40. Jung, C.H.; Lee, J.Y.; Cho, C.H.; Kim, C.J. Anti-asthmatic action of quercetin and rutin in conscious guinea-pigs challenged with aerosolized ovalbumin. Arch. Pharm. Res. 2007, 30, 1599-1607. [CrossRef] [PubMed]

41. Xiang, Z.; Ning, Z. Scavenging and antioxidant properties of compound derived from chlorogenic acid in South-China honeysuckle. LWT Food Sci. Technol. 2008, 41, 1189-1203. [CrossRef]

42. Nakagawa, K.; Ninomiya, M.; Okubo, T.; Aoi, N.; Juneja, L.R.; Kim, M.; Yamanaka, K.; Miyazawa, T. Tea catechin supplementation increases antioxidant capacity and prevents phospholipid hydroperoxidation in plasma of humans. J. Agric. Food Chem. 1999, 47, 3967-3973. [CrossRef] [PubMed]

43. Guo, L.; Wang, S.; Zhang, J.; Yang, G.; Zhao, M.; Ma, W.; Zhang, X.; Li, X.; Han, B.; Chen, N. Effects of ecological factors on secondary metabolites and inorganic elements of Scutellaria baicalensis and analysis of geoherblism. Sci. China Life Sci. 2013, 56, 1047-1056. [CrossRef] [PubMed]

44. Markom, M.; Hasan, M.; Daud, W.R.W.; Singh, H.; Jahim, J.M. Extraction of hydrolysable tannins from Phyllanthus niruri Linn.: Effects of solvents and extraction methods. Sep. Purif. Technol. 2007, 52, 487-496. [CrossRef]

45. Szakiel, A.; Paczkowski, C.; Henry, M. Influence of environmental abiotic factors on the content of saponins in plants. Phytochem. Rev. 2011, 10, 471-491. [CrossRef]

46. Aharoni, A.; Galili, G. Metabolic engineering of the plant primary-secondary metabolism interface. Curr. Opin. Biotechnol. 2011, 22, 239-244. [CrossRef] [PubMed]

47. Masoumian, M.; Arbakariya, A.; Syahida, A.; Maziah, M. Flavonoids production in Hydrocotyle bonariensis callus tissues. J. Med. Plants Res. 2011, 5, 1564-1574.

48. Zulak, K.G.; Weljie, A.M.; Vogel, H.J.; Facchini, P.J. Quantitative ${ }^{1}$ H NMR metabolomics reveals extensive metabolic reprogramming of primary and secondary metabolism in elicitor-treated opium poppy cell cultures. BMC Plant Biol. 2008, 8, 5. [CrossRef] [PubMed]

49. Payyavula, R.S.; Singh, R.K.; Navarre, D.A. Transcription factors, sucrose, and sucrose metabolic genes interact to regulate potato phenylpropanoid metabolism. J. Exp. Bot. 2013, 64, 5115-5131. [CrossRef] [PubMed]

50. Ferri, M.; Righetti, L.; Tassoni, A. Increasing sucrose concentrations promote phenylpropanoid biosynthesis in grapevine cell cultures. J. Plant Physiol. 2011, 168, 189-195. [CrossRef] [PubMed] 
51. Park, C.H.; Kim, Y.S.; Li, X.; Kim, H.H.; Arasu, M.V.; Al-Dhabi, N.A.; Lee, S.Y.; Park, S.U. Influence of Different Carbohydrates on Flavonoid Accumulation in Hairy Root Cultures of Scutellaria baicalensis. Nat. Prod. Commun. 2016, 11, 799-802. [PubMed]

52. Rice-Evans, C. Flavonoid antioxidants. Curr. Med. Chem. 2001, 8, 797-807. [CrossRef] [PubMed]

53. Rice-Evans, C.; Miller, N.; Paganga, G. Antioxidant properties of phenolic compounds. Trends Plant Sci. 1997, 2, 152-159. [CrossRef]

54. Torel, J.; Cillard, J.; Cillard, P. Antioxidant activity of flavonoids and reactivity with peroxy radical. Phytochemistry 1986, 25, 383-385. [CrossRef]

55. Kang, Y.-H.; Park, Y.-K.; Lee, G.-D. The nitrite scavenging and electron donating ability of phenolic compounds. Korean J. Food Sci. Technol. 1996, 28, 232-239.

56. Natella, F.; Nardini, M.; Di Felice, M.; Scaccini, C. Benzoic and cinnamic acid derivatives as antioxidants: Structure- activity relation. J. Agric. Food Chem. 1999, 47, 1453-1459. [CrossRef] [PubMed]

57. Kähkönen, M.P.; Heinonen, M. Antioxidant activity of anthocyanins and their aglycons. J. Agric. Food Chem. 2003, 51, 628-633. [CrossRef] [PubMed]

58. Park, C.H.; Baskar, T.B.; Park, S.-Y.; Kim, S.-J.; Valan Arasu, M.; Al-Dhabi, N.A.; Kim, J.K.; Park, S.U. Metabolic profiling and antioxidant assay of metabolites from three radish cultivars (Raphanus sativus). Molecules 2016, 21, 157. [CrossRef] [PubMed]

59. Park, C.H.; Yeo, H.J.; Baskar, T.B.; Kim, J.K.; Park, S.U. Metabolic Profiling and Chemical-Based Antioxidant Assays of Green and Red Lettuce (Lactuca sativa). Nat. Prod. Commun. 2018, 13, 315-322.

60. Akerele, O. Nature's medicinal bounty: Don't throw it away. World Health Forum 1993, 14, 390-395. [PubMed]

61. Ekor, M. The growing use of herbal medicines: Issues relating to adverse reactions and challenges in monitoring safety. Front. Pharmacol. 2014, 4, 177. [CrossRef] [PubMed]

62. Park, C.H.; Yeo, H.J.; Park, Y.J.; Morgan, A.; Valan Arasu, M.; Al-Dhabi, N.A.; Park, S.U. Influence of indole-3-acetic acid and gibberellic acid on phenylpropanoid accumulation in common buckwheat (Fagopyrum esculentum Moench) sprouts. Molecules 2017, 22, 374. [CrossRef] [PubMed]

63. Li, X.; Kim, J.K.; Park, S.-Y.; Zhao, S.; Kim, Y.B.; Lee, S.; Park, S.U. Comparative analysis of flavonoids and polar metabolite profiling of tanno-original and tanno-high rutin buckwheat. J. Agric. Food Chem. 2014, 62, 2701-2708. [CrossRef] [PubMed]

64. Cho, E.-K.; Choi, Y.-J. Physiological activities of hot water extracts from Ecklonia cava Kjellman. J. Life Sci. 2010, 20, 1675-1682. [CrossRef]

65. Yang, E.-J.; Yim, E.-Y.; Song, G.; Kim, G.-O.; Hyun, C.-G. Inhibition of nitric oxide production in lipopolysaccharide-activated RAW 264.7 macrophages by Jeju plant extracts. Interdiscip. Toxicol. 2009, 2, 245-249. [CrossRef] [PubMed]

Sample Availability: Samples of compounds are not available from the authors.

(C) 2018 by the authors. Licensee MDPI, Basel, Switzerland. This article is an open access article distributed under the terms and conditions of the Creative Commons Attribution (CC BY) license (http:// creativecommons.org/licenses/by/4.0/). 